GU J Sci, Part C, 6(4): 887-897 (2018)

Gazi Üniversitesi
Fen Bilimleri Dergisi
PART C: TASARIM VE TEKNOLOJI
http://dergipark.gov.tr/gujsc

\title{
Üretim Koşullarının Vermiküler Grafitli Dökme Demirin Mikro Ve Makro Yapısal Özelliklerine Etkileri
}

\author{
Berkay KARATAY ${ }^{1}$, Hasan HASIRCI ${ }^{2, *}$ \\ ${ }^{I}$ Gazi Üniv. Fen Bil. Enst. Met. ve Malz. Müh., ${ }^{2}$ Gazi Üniv. Teknoloji Fak. Met. ve Malz. Müh.
}

\begin{abstract}
$\ddot{O} \mathbf{z}$
Makale Bilgisi

Başvuru: 23/03/2018

Düzeltme: $10 / 6 / 2018$

Kabul: $12 / 11 / 2018$

Anahtar Kelimeler

Vermiküler

Yapısal özellikler Tane

boyutu

Matris

$\mathrm{Bu}$ makale, üretim şartlarının Vermiküler Grafitli Dökme Demir (VGDD) malzemenin üretilebilirliği ve yapısal özellikleri üzerine etkilerini göstermek için hazırlanmıştır. Bu malzeme ile hızlı tren fren diski üretimi amaçlandığı için, kullanım koşullarına uygunluk açısından \% 45-50 vermikülerleşme yeterli kabul edilmiştir. Çünkü bu malzemelerden daha yüksek dayanım gibi nispeten daha iyi mekanik özellikler istenmektedir. $\mathrm{Bu}$ çalışmada kullanılmak üzere, tarafımızdan Ver-Mat olarak isimlendirilen bir vermikülerleştirci malzeme geliştirilmiş ve döküm potasında ilave edilerek VGDD numuneler üretilmiştir. Bu amaçlarla, farklı oranlarda vermikülerleştirici ilave edilerek istenilen malzeme üretimi gerçekleştirilmiştir. Daha sonra, uygun olan malzemeye farklı oranlarda FeSi aşılayıcı (\% 0.3, 0.5 ve 0.8 ) ve $\% 0.5$ $\mathrm{Cu}$ ilavesi yapılarak mikro ve makro yapısal değişimler de incelenmiştir. Deneysel sonuçlara bakıldığında; vermikülerleştirici ilavesindeki artışa bağlı olarak istenilen biçimde VGDD üretimi başarıyla gerçekleştirilmiştir. FeSi aşılayıcı miktarına bağlı olarak tane sayısının arttı̆g 1 ve vemiküler grafitlerin hedeflenen ölçülerde üretilebildiği tespit edilmiş̧tir. Ayrıca, $\mathrm{Cu}$ ilavesi nedeniyle matris yapı ferritik yerine ferrit+perlitik olmuştur.
\end{abstract}

Keywords

Vermicular

Structural properties

Grain size

Matrix
Effects Of Production Conditions On Micro And Macro Structural Properties Of Compacted Graphite Cast Iron

\begin{abstract}
This paper is prepared to show the effects of production conditions on the manufacturability and structural properties of Compacted Graphite Cast Iron (CGI) material. Since this material is intended for high speed brake disc production, $45-50 \%$ vermiculization is regarded as sufficient for suitability for the usage conditions. Because they require relatively good mechanical properties such as higher strength than these materials. For use in this work, we have developed a vermicularising material called Ver-Mat and added CGI specimens in the casting cruciple. For these purposes, the desired materials were produced by adding vermiculariser at different ratios. Subsequently, micro- and macro-structural changes were investigated by applying $\mathrm{FeSi}$ inoculants $(0.3 \%, 0.5 \%$ and $0.8 \%)$ and $0.5 \% \mathrm{Cu}$ addition to the appropriate material. Considering the experimental results; CGI production has been successfully accomplished in the desired structure depending on the increase in the addition of the vermiculariser. It has been found that the number of grains increases with the amount of $\mathrm{FeSi}$ inoculate and that the vermiculated graphite can be produced at the targeted scale. Moreover, due to the addition of $\mathrm{Cu}$ the matrix structure has become ferrite+pearlitic instead of ferritic.
\end{abstract}

\section{GİRIŞ̧ (INTRODUCTION)}

Gri Dökme Demir'ler (GDD) çok farklı ve iyi mekanik ve yapısal özellikleri nedeniyle çok geniş ve yaygın kullanım alanına sahiptirler. $\mathrm{Bu}$ nedenle hemen her sektörde yapısal malzeme olarak kullanılmaktadırlar. Özellikle Küresel Grafitli Dökme Demir'ler (KGDD) hem döküm hem de 1sıl işlem uygulamasıyla birlikte çok üstün özelliklere sahip olabildiklerinden dolayı en fazla tercih edilen türdür. Lamel Grafitli Dökme Demir'ler (LGDD) ise özellikle basma dayanımları ve 1sıl iletkenlikleri nedeniyle tercih edilmektedir. KGDD ve LGDD'in grafit yapısı bakımından ara türü olan VGDD'ler ise mekanik ve 
termal özellikler bakımından her iki dökme demirin ara bir formudur. Bu nedenlerle çok tercih edilen yapısal malzemelerdendir. Son yıllarda özellikle dökme demir dizel motor parçaları, manifoldlar, fren diskleri vb. sıcak ortamda çalışan veya çalışma sırasında ısınan parçaların imalatında sıkça kullanılmaktadır. Bu malzemeler çalışma sırasında üzerlerine etkiyen ya da oluşan 1sıyı mekanik ve yapısal özelliklerinin bozulmaması için hızlıca uzaklaştırmaları gerekmektedir. Bu nedenlerle mekanik hem de 1 sıl iletimlerinin olabildiğince yüksek olması gerekmektedir [1-17].

$\mathrm{Bu}$ özellikleri sağlayan asıl unsurlar; matris yapı (çoğunlukla ferritik, ferrit +perlitik ve çoğunlukla perlitik) ile vermiküler grafit miktarı ve şeklidir. Bir dökme demirin tam olarak VGDD olarak kabul edilmesi için vermikülerleşme oranının genellikle \% 80-90 olması gerektiği ifade edilmektedir [1, 5, 8]. Ancak bu gereksinimin hangi şartlar için olacağı veya başka bir ifadeyle nasıl ve ne gibi özelliklerde bir parça için kabul edildiği açık değildir. Örneğin motor gövdesi, kampana ve fren diski için farklı özellikler istendiğine göre bu parçaların üretileceği malzeme standartının da farklı olması doğaldır. Bu nedenle VGDD malzemenin de birçok çeşidi (ISO 16112 standartına göre; GJV300, GJV350, GJV400, GJV450, GJV500) mevcuttur. Bunların matris yap1ları ferritik (GJV300), ferrit+perlitik (GJV350-450) ve perlitik (GJV500) olarak değişmektedir. Bu matris yapılarına bağlı olarak mekanik ve fiziksel özellikleri de değişim göstermektedir [18-24]. Matris yapıyı çoğunlukla perlitik yapmadan, özellikle dayanım özelliklerinin geliştirilmesi için küresel grafit oranının \% 30-45 oranında olması faydalı olacaktır.

VGDD'ler farklı üretim metot ve malzemeleri kullanılarak üretilebilmektedir. Bu malzemelerden bazıları; BJOMET, LAMET ve en yaygınlarından biri olan COMPACTMAG ticari isimlidir. En başarılı ve yaygın yöntemler ise; tel tretman, in-mold ve pota olmak üzere temelde 3 farklı uygulama şeklinde yapılmaktadır. Vermikülerleştirme işlemi küreselleştirmeden sonra tersine mühendislik mantığıyla yapılabildiği gibi, doğrudan vermikülerleştirme şeklinde de yapılabilmektedir [14-27]. Vermiküler grafit oranı arttıkça mekanik özellikler bir miktar azalırken, 1sıl iletimi gibi bazı fiziksel özellikler gelişmektedir. Bu nedenle küresel/vermiküler grafit oranı iyi bir şekilde ayarlanmalıdır. Aynı zamanda mekanik ve fiziksel özellikler matris yapısı ve tane boyutuna da bağlıdır. Matriste perlit miktarının artması ve tane boyutunun azalması ile birçok mekanik ve fiziksel özellik geliştirilebilir. Isıl iletkenlik de matris yapı ve tane boyutuna da bağlı değişebilecek bir olgudur. VGDD'lerin 1sıl iletkenlikleri ile ilgili çalışmalar [1-3,10-17,25-27] incelendiğinde; bunların genellikle KGDD ile VGDD malzemelerin karşılaştırılması ve uygulanan sıcaklığa bağlı değişimlerin olduğu görülmektedir. Özellikle matris yapı (ferritik $\rightarrow$ perlitik), grafit boy/en oranı, grafit/matris oranı, tane boyutu, küreselleşme oranı gibi değişkenlere bağl1 1 sıl iletkenliğin değişimi inceleme konusu yapılmadığı görülmektedir.

VGDD uzun yıllardan bu yana bilinmesine ve çeşitli araştırmalar yayınlanmış olmasına rağmen [1-4,1825], yukarıda da ifade edildiği gibi VGDD'in bazı özellikleri KGDD ve LGDD’ler kadar iyi bilinmemektedir. $\mathrm{Bu}$ çalışmada, hızlı tren fren disklerinde kullanılmak üzere standartların dışında özelliklere sahip ve kendi geliştirdiğimiz özel malzeme karışımı kullanılarak VGDD üretimi gerçekleştirilmesi amaçlanmaktadır. Bu makale, hedeflenen amaca uygun olarak yapılan çalışmaların ilk aşaması olan malzeme üretim ve yapısal karekterizasyon çalışmalarını içermektedir. $\mathrm{Bu}$ amaçla; vemikülerleştirme işlem şartları, \% 0.5 oranında $\mathrm{Cu}$ ve farklı oranlardaki aşılayıcı ilavesinin grafitin vermikülerleşmesi, grafit miktarı, tane sayısı ve boyutuna, ferrit ve perlitik yapı oluşumuna etkileri makro ve mikro yapısal açıdan incelenmiştir.

\section{DENEYSEL ÇALIŞMALAR (EXPERIMENTAL PROCEDURE)}

Dökümün yapıldığı kalıp tasarımı TS 526 EN 1563'e belirtilen Y-blok şeklinde hazırlanmıştır (Şekil 1). Üretilen numuneler ve uygulanan işlemler ile ilave edilen malzemeler Tablo 1'de özet halinde verilmiştir. Ergitme işlemi $1000 \mathrm{Kg}$ kapasiteli ergitme tipi indüksiyon ocağı kullanılarak yapılmıştır. İndüksiyon ocağına şarj girdisi olarak; külçe şeklinde $\% 80$ sfero piki ve $\% 20 \mathrm{H} 2$ piki doldurulmuş ve ergitilmiştir. Ergitilen sıvı dökme demirin kimyasal bileşimi Tablo 2'de verilmiştir.

Ergitilmiş metal, döküm sıcaklığına ulaştıktan sonra $\left(1450{ }^{\circ} \mathrm{C}\right)$ aşılama ve küreleştirme işlemleri yapılmıştır. Küreleştirme işlemi Tundish tipi işlem potasında gerçekleştirilmiştir. Küreleştirme işleminde FeSiMg malzemesi kullanılmıştır. Deneysel çalışmalar öncelikle KGDD üretimi (numune A) ile başlanmıştır. Daha sonra bu KGDD malzemesinin vermikülerleştirilmesi ile istenilen VGDD (numune $\mathrm{B} 1, \mathrm{~B} 2$ ve $\mathrm{B} 3$, sırasıyla $\% 0.3,0.5$ ve 0.8 vermikülerleştirici içeren) üretiminin yapılabilirliği denenmiştir. 
$\mathrm{Bu}$ amaçla bu çalışma için hazırlanmış vermikülerleştirici malzeme (Al, Mg, Ti, B, S, Si, Fe) karışımına Ver-Mat adı verilmiştir. Elde edilen başarılı sonuçlardaki ilave Ver-Mat oranılla (\% 0.5$)$ ve tane boyutunun değiştirilebilmesi amacıyla 3 farklı aşılayıcı ilavesiyle VGDD (numune C1, C2 ve C3) üretimi gerçekleştirilmiştir. Daha sonra aynı vermikülerleştirci ve aşılayıcı oranlarına ilaveten $\% 0.5 \mathrm{Cu}$ ilavesi yapılarak ferrit+perlitik matrise ve aynı zamanda 3 farklı tane boyutuna sahip VGDD (numune D1, D2 ve D3) üretilmiştir. Aşılama işlemleri; standart FeSi malzemesi kullanılarak 2 aşamada gerçekleştirilmiştir. İlk aşılama Tundish potasında \% 0.3 ilave yapıldıktan sonra bir numune alınmış, ardından döküm potası tabanına önce $\% 0.5$ ve sonra ise $\% 0.8$ oranında konularak numuneler dökülmüştür. Vermikülerleştirici Ver-Mat malzemesi granül halinde döküm potasında, pota tabanına $\% 0.3,0.5$ ve 0.8 oranlarında konularak reaksiyona girmesi sağlanmış, karıştırma yapılmış ve 1.5-2 dakika beklendikten sonra kalıplara dökülmüştür.

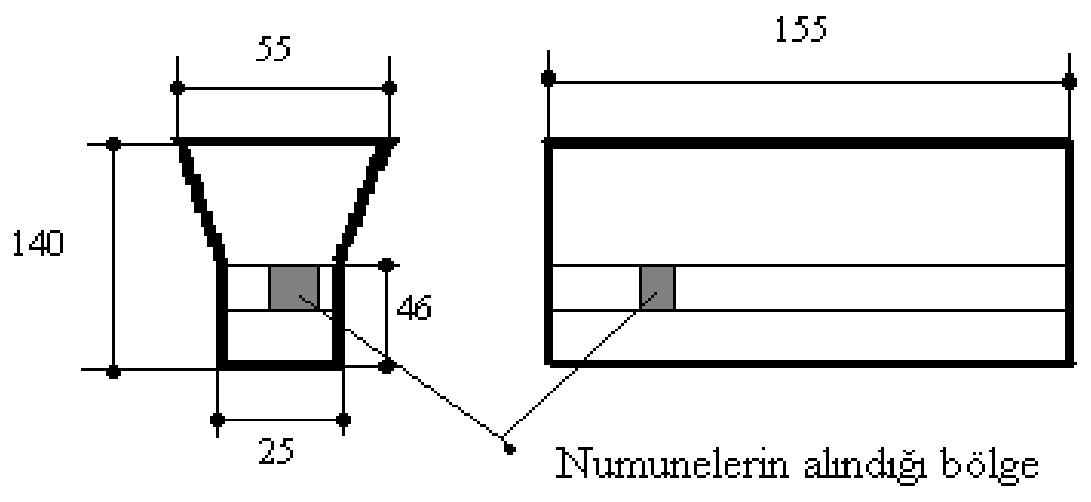

Şekil 1. Y-blok tasarımı (TS 526 EN 1563)

Numunelerin dökümü sırasında kimyasal bileşimin tespiti için ayrıca spektral analiz numuneleri dökülmüş ve numunelerin Spectrolab marka spektrometre ile 3 adet ölçümden elde edilen ortalama kimyasal bileşimleri Tablo 2'de verilmiştir. Üretilen numunelerin matris yapısı, grafit şekli ve dağılımı ile ilgili metalografik ölçümler Y-blok üzerinden Şekil 1'de verilen bölgeden alınan numuneler üzerinde standart polisaj işlemlerinin (220-1200 mesh zımparalama ve $3 \mu \mathrm{m}$ 'lik keçelerde parlatma) tamamlanmasından sonra yapılmıştır.

Tablo 1. Bu çalışma için üretilen numunelere uygulanan işlemler

\begin{tabular}{|c|c|}
\hline Numune Kodu & Detaylı bilgi \\
\hline $\mathbf{A}$ & KGDD \\
\hline B1 & VGDD (\%0.3 vermikülerleştirci + 0,5 aşılayııı ilaveli) \\
\hline B2 & VGDD (\%0.5 vermikülerleştirci $+0,5$ aşılayıcı ilaveli \\
\hline B3 & VGDD (\%0.8 vermikülerleştirci $+0,5$ aşılayıcı ilaveli \\
\hline C1 & VGDD (\%0.5 vermikülerleștirci + 0,3 aşılayııı ilaveli) \\
\hline C2 & VGDD (\%0.5 vermikülerleştirci + 0,5 aşılayıcı ilaveli) \\
\hline C3 & VGDD (\%0.5 vermikülerleştirci + 0,8 aşılayıcı ilaveli) \\
\hline D1 & VGDD ( $\% 0.5$ vermikülerleştirci $+0,3$ aşılayıı ilaveli $+\% 0.5 \mathrm{Cu})$ \\
\hline D2 & VGDD (\%0.5 vermikülerleştirci $+0,5$ aşılayıcı ilaveli $+\% 0.5 \mathrm{Cu})$ \\
\hline D3 & VGDD ( $\% 0.5$ vermikülerleştirci $+0,8$ aşılayıcı ilaveli $+\% 0.5 \mathrm{Cu})$ \\
\hline
\end{tabular}

Birim alandaki grafit sayısı ve şekliyle ilgili analizler dağlanmamış, matris yapısı ile ilgili analizler ise \% 2 nital ile dağlanmış numune yüzeyinden x100 büyütmede 10 ayrı bölgeden Leica marka mikroskop ile elde edilen dijital görüntülerden mikroskobun kendi görüntü analizi ve ImageJ yazılımları kullanılarak belirlenmiştir. Tane boyutu ölçümleri x100 büyütmede ASTM E 112 standartına göre yapılmıştır. 
Tablo 2. Bu çalışma için üretilen numunelerin kimyasal bileşimleri

\begin{tabular}{r|rrrrrrr} 
Numune kodu & $\% \mathrm{C}$ & $\% \mathrm{Si}$ & $\% \mathrm{Mn}$ & $\% \mathrm{P}$ & $\% \mathrm{~S}$ & $\% \mathrm{Cu}$ & $\% \mathbf{F e}$ \\
\hline A, B1, B2, B3, C1, C2 ve C3 & 3.5 & 2.6 & 0.164 & 0.026 & 0.007 & - & Kalan \\
D1, D2, D3 & 3.5 & 2.6 & 0.164 & 0.026 & 0.007 & 0.5 & Kalan
\end{tabular}

\section{DENEYSEL SONUÇLAR VE TARTIŞMA (EXPERIMENTAL RESULTS AND DISCUSSION)}

\subsection{VGDD'in Üretilebilirliği (Producibility of CGI)}

Gri dökme demirin 3 farklı türüne ait grafit yapıları şematik olarak Şekil 2'de verilmektedir. Şekil incelendiğinde; grafit şeklinin küreselden çizgisel şekle doğru değiştiği ve bu grafit şekline göre dökme demirlere sırasıyla KGDD, VGDD ve LGDD adı verilmektedir. Her üç dökme demir de kendine has özellikleri nedeniyle endüstride çok miktarda talep edilen malzeme türlerindedir. Bu çalışmanın konusu olan VGDD; küre ile lamel arasında bir grafit şekline sahip olduğu için termal ve elektriksel iletkenlik, basma dayanımı KGDD'den yüksek, buna karşın süneklik, çekme ve akma dayanımı KGDD'den düşüktür. LGDD ile kıyaslandığında ise; termal ve elektriksel iletkenlik, basma dayanımı düşük, buna karşın süneklik, çekme ve akma dayanımı yüksektir. Dolayısıyla özellikle orta derecede mekanik ve fiziksel özellikler nedeniyle talep edilen bir malzemedir. Bu malzemede grafit şekli ucu küremsi lamele (bazı tabirlere göre solucanımsı) benzemektedir. Bu nedenle genel olarak LGDD'den daha iyi mekanik özelliklere sahiptir. Yapısında vermiküler grafitlerin yanı sıra bir miktar (standartlarda \% 20'den az kabul edilmektedir) küresel grafit de bulunmaktadır. Küresel grafit miktarına bağlı olarak mekanik özellikleri daha da geliştirilebilmektedir [1-5, 7-9].

Şekil 2'de gösterildiği gibi vermiküler grafitler küresel grafitler gibi 3 boyutlu yapılardır [14]. Bunun aksine; lamel grafitler ise iki boyutlu sivri uçlu yapılardır. VGDD'in kısmen bu 3 boyutlu grafit yapısı nedeniyle mekanik özellikleri LGDD'den daha iyidir.

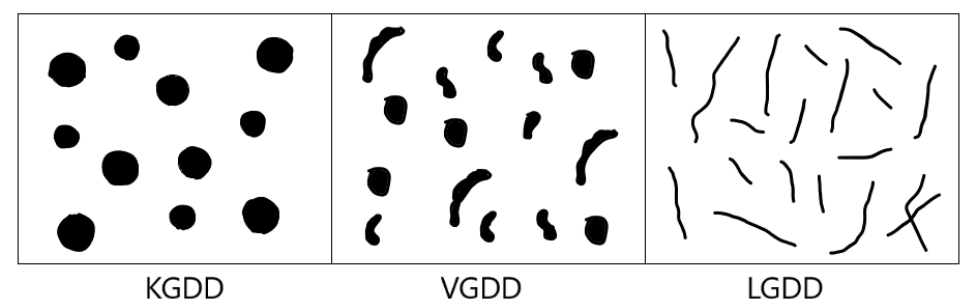

Şekil 2. Grafit morfolojilerine göre dökme demirlerin sınıflandırılması

Vermiküler grafitler (Şekil 3), bir metalografi mikroskopu ile görüntülendiğinde bağımsız solucan benzeri görünse de, derin dağlama sonrası SEM görüntülerine bakıldığında bu grafitlerin matris hücre içindeki en yakın komşularına bağlandığı görülmektedir. Bu karmaşık ve bağlantılı grafit morfolojisi, yuvarlak kenarlı ve düzensiz engebeli yüzeyler nedeniyle, grafit ile demir matrisi arasında kuvvetli bir mekanik ve kimyasal yapışmanın oluşmasına yol açar. Keskin uçlu olmayan grafit morfolojisi; hem çatlak başlatma hem de yayılımını engellemeye yardımcı olduğundan dolayı, LGDD ile karşılaştırıldığında VGDD'in daha gelişmiş mekanik özelliklere sahip olmasına neden olmaktadır.
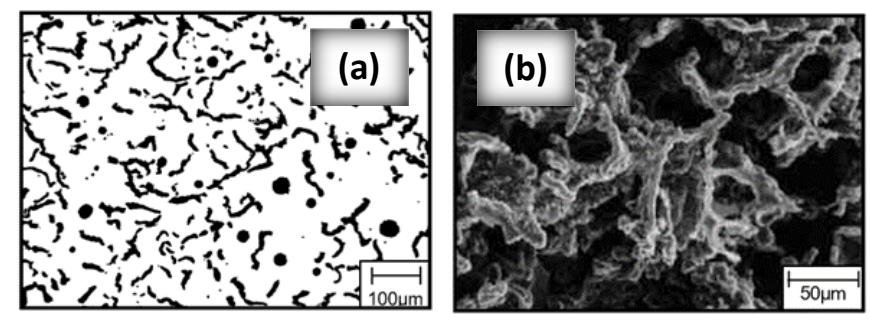

Şekil 3. Vermiküler grafitin, (a) optik ve (b) SEM mikroskobu görüntüleri [14] 
Vermikülerleştirme sonucunda grafit morfolojinin değişim daha sonraki bölümde (Böl. 3.2.) geniş olarak anlatılacaktır. Kısaca bahsetmek gerekirse; bu çalıșmada vermikülerleştirme işlemi ve Ver-Mat malzeme miktarının artması sonucunda vermiküler şekilli grafit oluşumu ve bu grafitin miktarı artmış, küresel şekilli grafit miktarı ise azalmıştır. Bu çalışma kapsamında hiç lamel grafit oluşumu gözlenmemiştir. Dolayısıyla istenilen özellikte ve miktarda VGDD başarıyla üretilmiştir.

\subsection{Mikro ve Makro Yapısal Özellikler (Properties of Micro and Macro Structural)}

Üretim şartlarına bağlı olarak elde edilen grafitlerin şeklindeki değişimler Şekil 4'de verilmektedir. Dağlanmamış mikroyapılar incelendiğinde; genel olarak vermikülerleştirme neticesinde hedeflenen VGDD'lerin üretilebildiği görülmektedir. Başlangıçta küresel olan grafit yapısı (A), Ver-Mat malzemesi ilavesi sonucunda vermiküler şekline dönüşmüştür. Ver-Mat malzeme miktarının artmasıyla (B1, B2 ve B3) birlikte; vermikülerleşme miktarının da arttığı tespit edilmiştir. Aşılayıcı miktarının artmasına bağlı olarak (C1-C3 ve D1-D3); vermiküler grafit sayısında bir artış ve boyunda ise küçülme meydana gelmiştir.
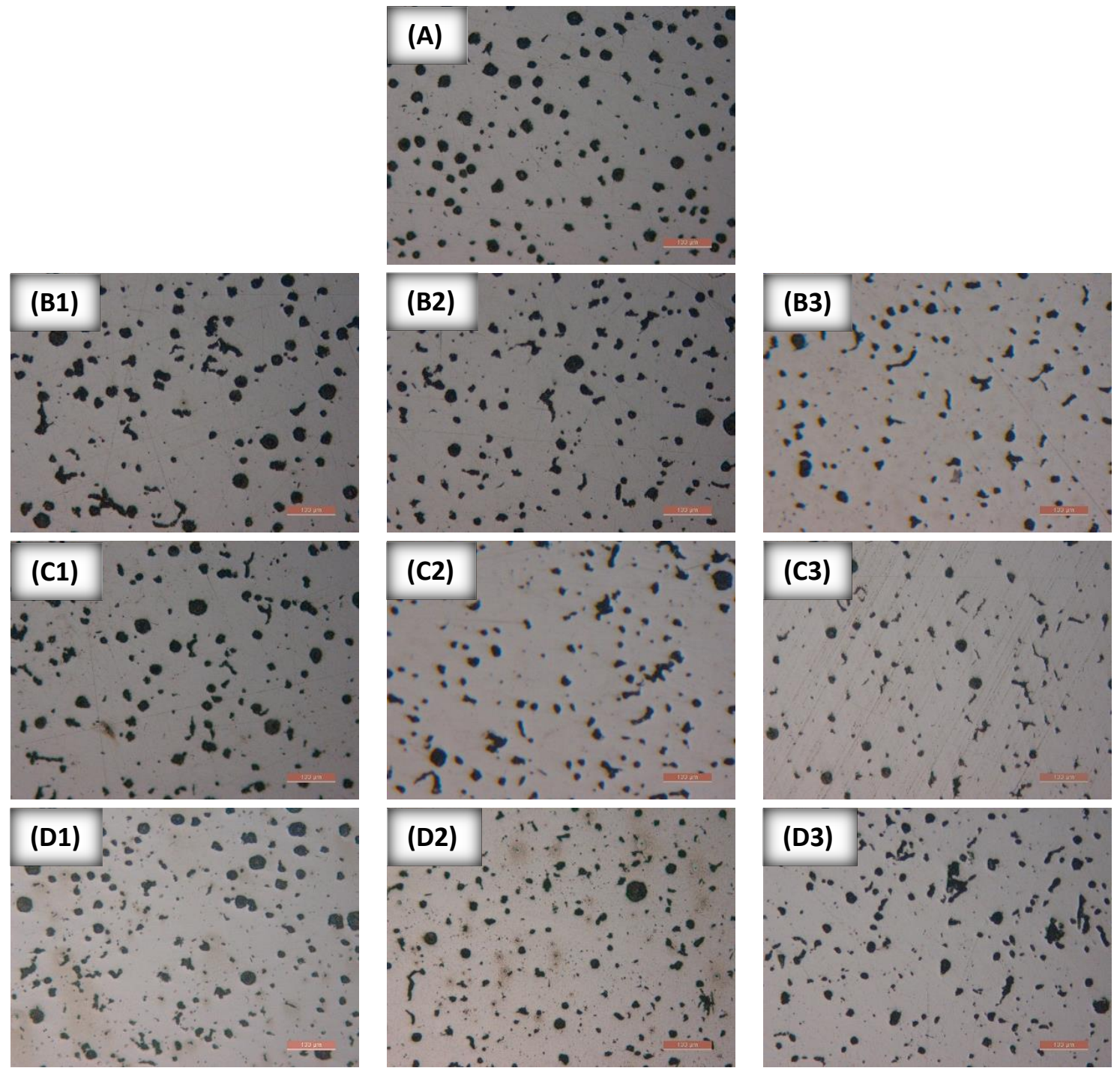

Şekil 4. Kimyasal bileşim değişmeden üretim şartlarına bağlı olarak grafit yapısının değişimi (Dağlamasız, X10)

Meydana gelen bu değişimlerin boyut, şekil ve miktar açısından değerlendirilmesi Şekil 5'te verilmiştir. $\mathrm{Bu}$ sonuçlara göre; \% vermiküler grafit oranı şekil açısından değerlendirme yapıldığında, 
vermikülerleştirme işlemi ve bu işlemde ilave edilen malzeme miktarının artmasına bağlı olarak vermiküler grafit sayısı artmış, buna karşın matrise karşılık grafit hacim oranı ise azalmıştır.

İdeal vermikülerleştirici oranı ve farklı miktarda aşılayıcı kullanıldığında; aşılayıcı miktarındaki artışa bağlı olarak grafit sayısında artış olurken, grafit boy/en oranı ile azda olsa grafit/matris oranında bir azalma meydana geldiği tespit edilmiştir. Gri dökme demirlerin katılaşması neo ötektik katılaşma ile başlamaktadır [28]. Buna göre katı östenit tanecikleri oluşurken aynı zamanda grafit fazı da meydana gelmektedir. Aşılayıcı miktarının artmasıyla birlikte, çok sayıda çekirdek oluşumuna bağlı olarak tane sayısı artarken, genellikle bu tanelerin arasında büyümeye çalışan grafitler de fazla büyüyemediğinden boyutları küçülmekte, ancak sayılarında artış meydana gelmektedir. Grafit/matris hacim oranı hemen hemen aynı olmasına karşın, aşılayıcı miktarının artmasına bağlı olarak çok sayıda grafik oluşuna bağlı olarak daha çok sayıda ancak kısa boyutlu grafitler meydana gelmektedir. Bu nedenle, aşılayıcı miktarının artması grafit boy/en oranını azaltmaktadır. Diğer yandan, perlit oluşumunu teşvik etmesi nedeniyle $\mathrm{Cu}$ ilavesinin de aşılayıcı ilavesi gibi grafit/matris hacim oranını bir miktar azalttığı görülmektedir. Bu durum grafitleşmeyi de bir miktar azalttığından grafit hacmin yanında boy/en oranında da bir miktar azalmaya neden oluşturmaktadır.

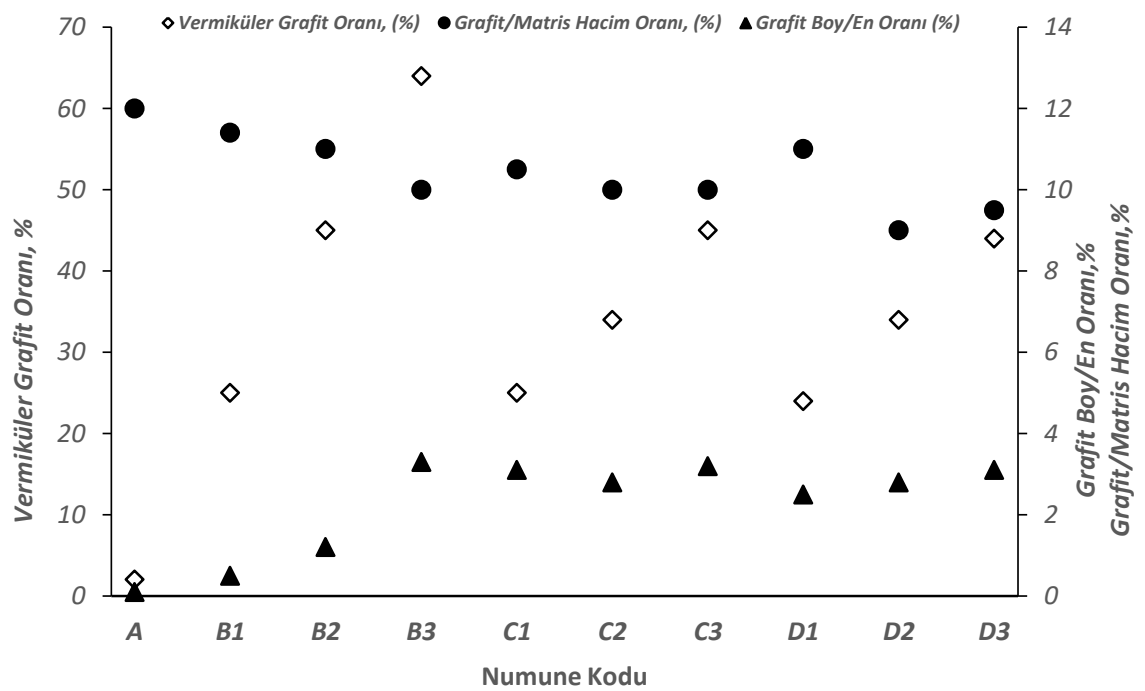

Şekil 5. Üretim şartlarının grafit yapısı, sayısı ve şeklinde meydana getirdiği değişimler

Çalışma kapsamında; üretim şartlarına bağlı olarak ve özellikle aşılayıcı miktarındaki değişime bağlı olarak VGDD malzemelerin makro yapılarındaki (tane boyutu) değişimler de incelenmiş ve sonuçlar Şekil 6 ve 7'de verilmiştir. Şekil 6'da özellikle tane boyutunun değişiminin gösterilmesi amacıyla aşılayıcı miktarı değiştirilerek üretilen numunelerin görüntüleri verilmiştir. Sonuçlar incelendiğinde aşılayıcı ilavesindeki artışla birlikte çekirdekleşme ve çekirdek sayısında meydana gelen artışa bağlı olarak tane sayısı artmış ve boyutu ise küçülmüştür. $\mathrm{Cu}$ ilavesinin tane sayısındaki artışa etkisinin olmadığı elde edilen sonuçlardan açıkça görülmüştür. $\mathrm{Cu}$ ilave edilmemiş (C1-C3) ve edilmiş (D1-D3) VGDD malzemeler kıyaslandığında tane sayısı ve boyut sonuçları arasında pek fark oluşmadığı, hemen hemen aynı sonuçların elde edildiği görülmüştür.

Döküm işlemlerinde yapılan her işlem az ya da çok matris yapıyı da etkilemektedir. Bu çalışmada özellikle matris yapısının değiş̧imi için $\mathrm{Cu}$ ilavesi yapılmıştır. Dökme demirlerde matris yapıları ifade edilirken grafit ilave edilmemektedir. Ancak bu malzemelerin özelliklerinin belirleyen en önemli yapısal elemanlardan birisi grafittir. $\mathrm{Bu}$ nedenle bu çalışmada matris ifade edilirken grafitte ilave edilerek verilmiştir. $\mathrm{Cu}$ miktarı sabit tutularak G+ağırlıklı Ferritik matrisli VGDD yanı sıra G+Ferrit+Perlitik matrisli VGDD üretilmiştir (Tablo 3, Şekil 8 ve 9). Bu çalışmada özellikle perlit oluşturmak için ilave edilen $\mathrm{Cu}$ nedeniyle perlit miktarı \% 48-50 oranlarına yükselmiştir (Şekil 10). Burada aynı zamanda aşılayıcı miktarı da benzer şekilde değiştirilerek değişim gözlenmiştir. 

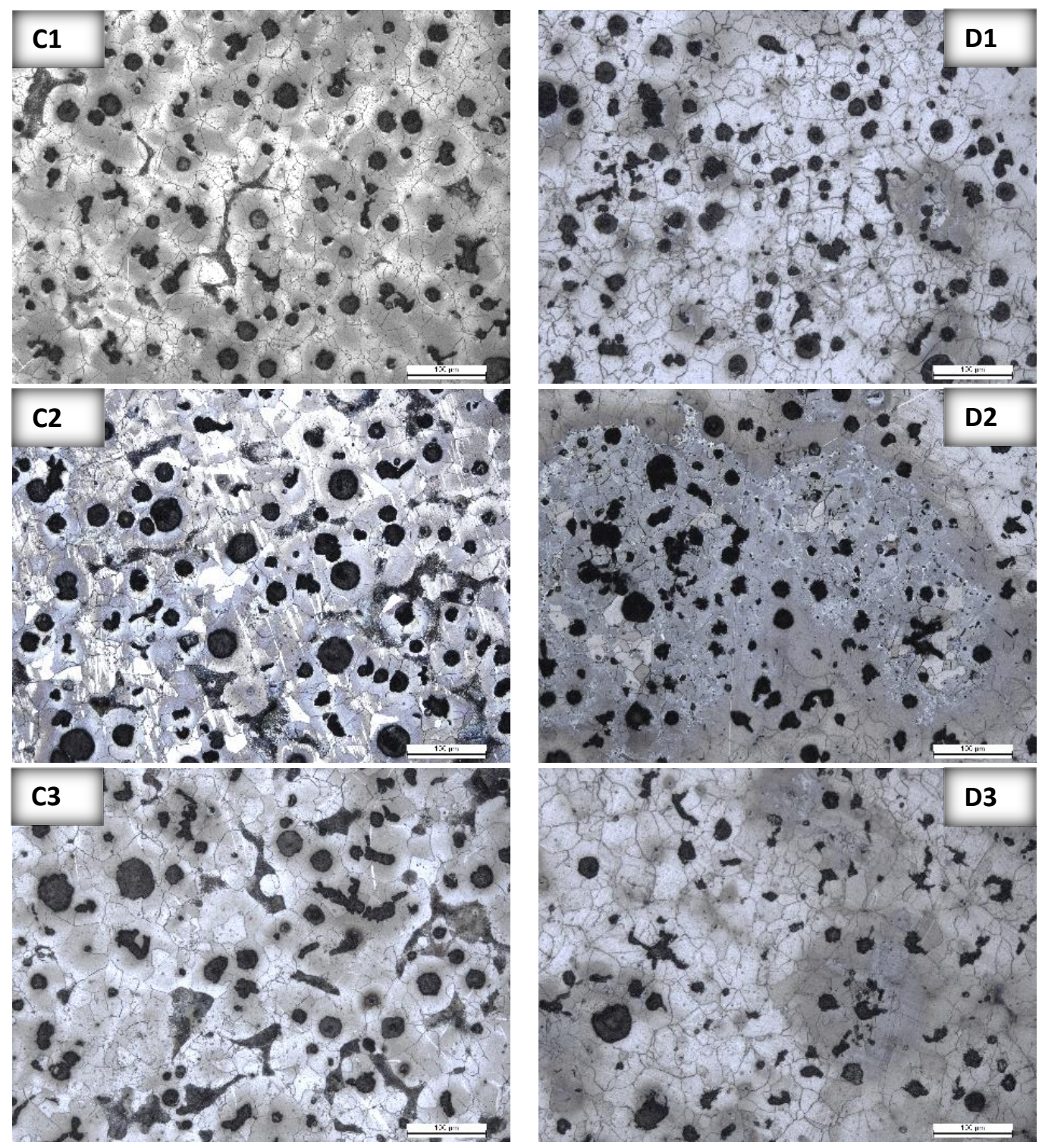

Şekil 6. VGDD’lerde aşılayıcı miktarına bağlı olarak tane boyutunun değişimi (\% 2 Nital, X10)

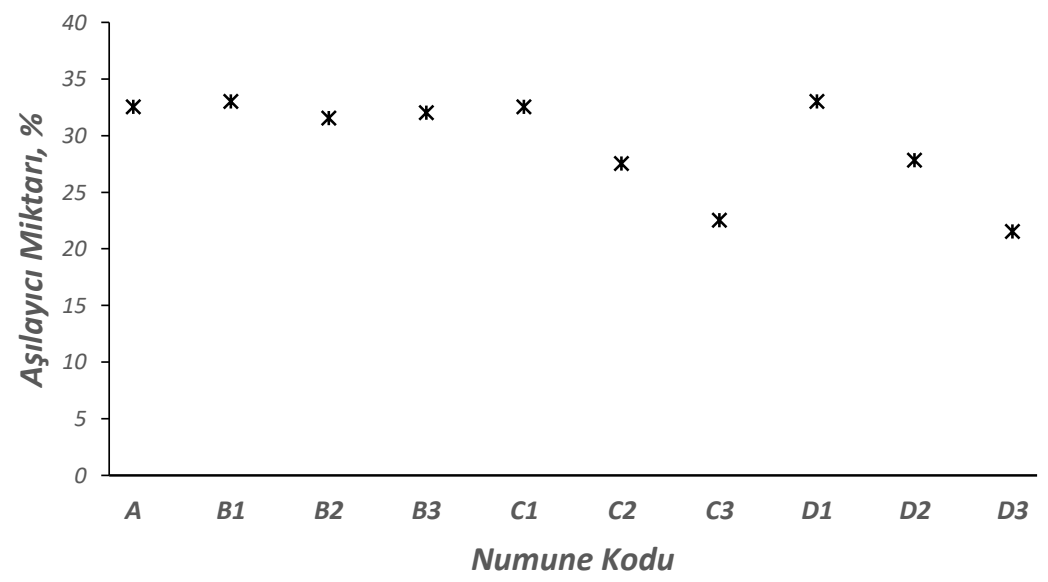

Şekil 7. Aşılayıcı miktarına bağlı olarak tane boyutunun değişimi 

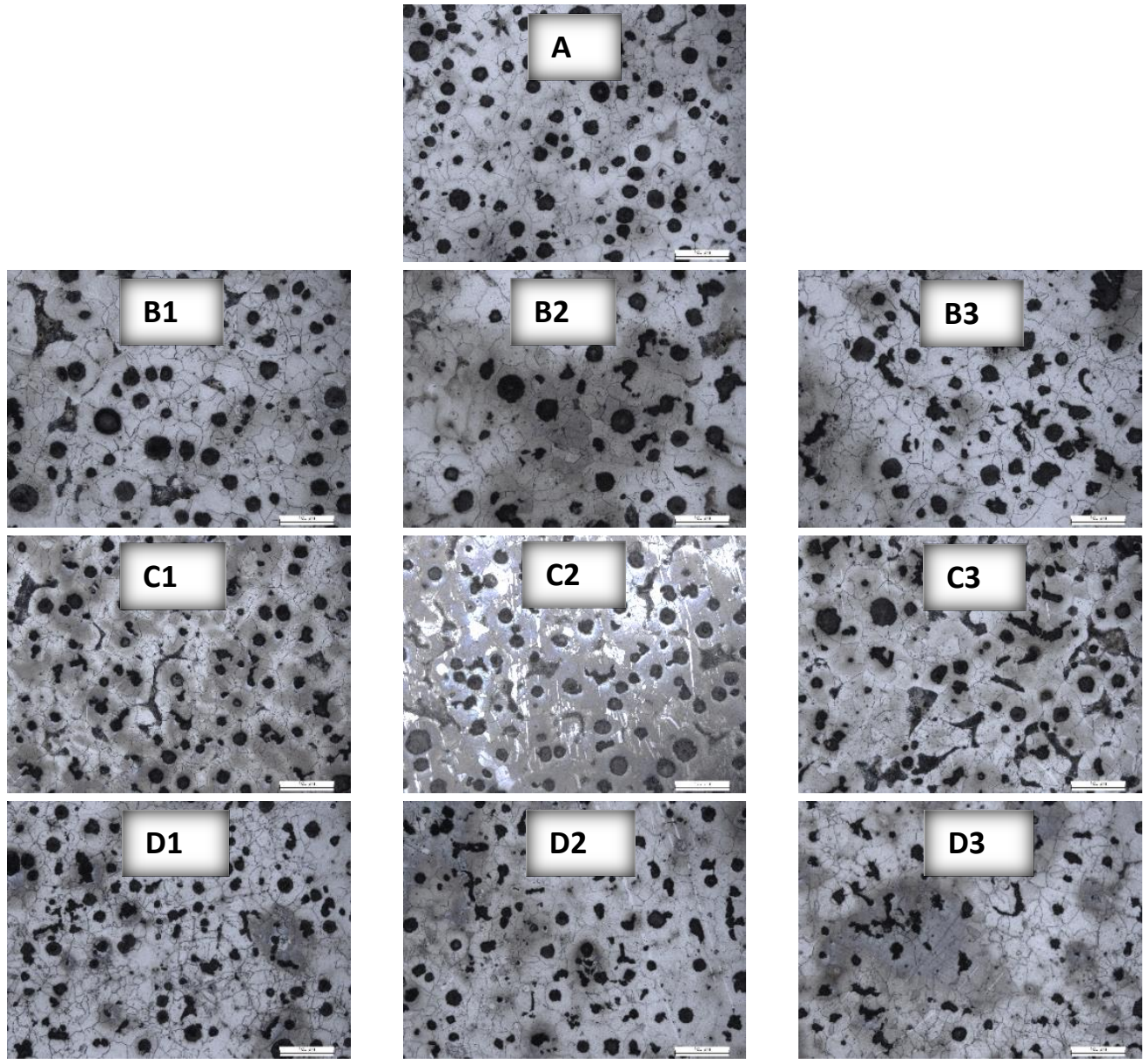

Şekil 8. Üretim şartlarına bağlı olarak matris yapısının değişimi (\% 2 Nital, X10)

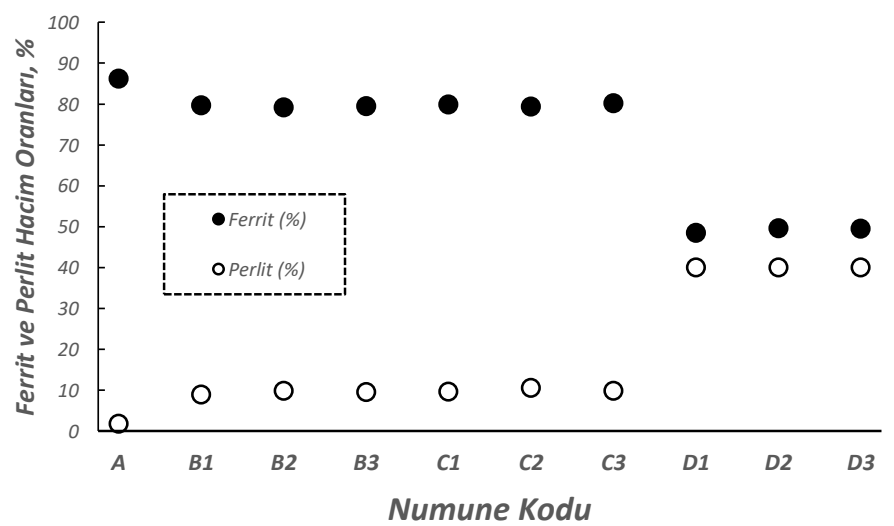

Şekil 9. Cu ilavesi ve aşılayıcı miktarına bağlı olarak matris yapısının değişimi
Tablo 3. Üretilen numunelerin matris yapıları

\begin{tabular}{c|c} 
Numune Kodu & Matris \\
\hline A & G + Ferritik \\
B1 & G + ağırlılı Ferritik \\
B2 & G + ağırlıklı Ferritik \\
B3 & G + ağırlıklı Ferritik \\
C1 & G + ağırlıklı Ferritik \\
C2 & G + ağırlık1 Ferritik \\
C3 & G + ağırlık1 Ferritik \\
D1 & G + Ferritik+Perlitik \\
D2 & G + Ferritik+Perlitik \\
D3 & G + Ferritik+Perlitik
\end{tabular}

Sonuçlar incelendiğinde; ağırlıklı olarak G+Ferritik (ortalama \% $12+87$ ) olan KGDD'in (numune A) matris yapısı, Ver-Mat vermikülerleştirici ilave sonucunda ağırlıklı olarak G+Ferrit+Perlitik (ortalama \% 10-12 + 79-81 + 8-10) matrise sahip VGDD'e (numune B1-B3 ve C1-C3) dönüşmüştür. Çünkü Ver-Mat malzemesinin kimyasal bileşiminde az da olsa perlit teşvik edici elementlerin bulunması nedeniyle perlit oluşumu teşvik edilmiştir. Aşılayıcı ilavesinin etkisine bakıldığında herhangi bir değişimin olmadığı görülmüştür. Çünkü aş1layıcı malzeme içeriğinde sementit yerine grafitleşmeyi teşvik edici özellikle Si gibi elementlerin varlığ 
G+Ferritik+Perlitik (ortalama \% 9-11 + 79-81 + 8-10) olmasına rağmen, $\mathrm{Cu}$ ilavesiyle birlikte G+Ferrit+Perlitik (ortalama \% 9-11 + 48-49 + 40-41) matrise sahip VGDD'e (numune D1-D3) dönüşmüştür.

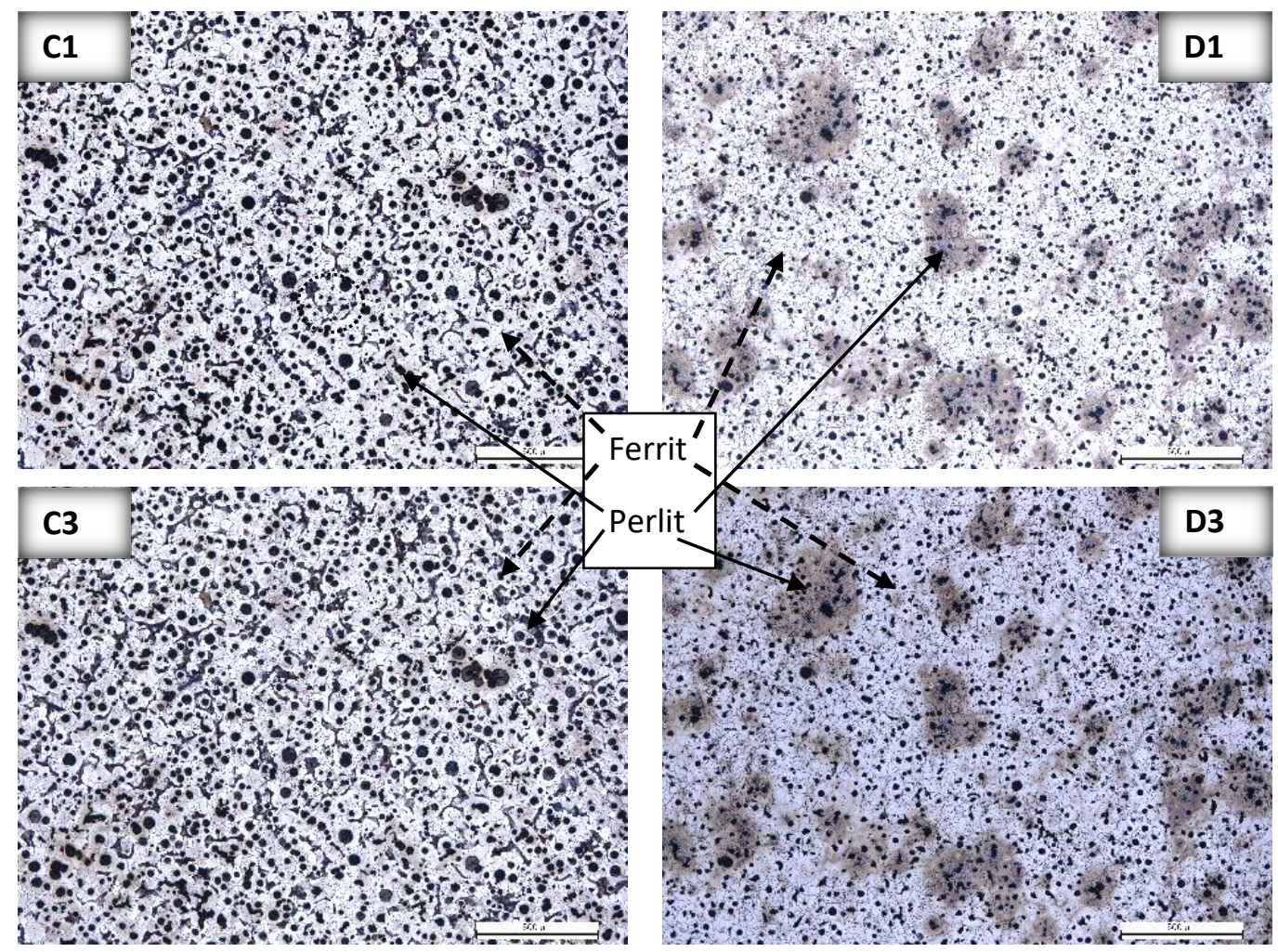

Şekil 10. Cu ilavesine bağlı olarak matris yapısının değişimi, (C1) İlavesiz ve (D1) $\mathrm{Cu}$ ilave edilmiş (Ferrit: açık beyaz alanlar, Perlit: koyu alanlar) (\% 2 Nital, X2,5)

\section{SONUÇLAR (CONCLUSIONS)}

Dökme demirlerin mekanik ve fiziksel özelliklerinin belirlenmesinde grafit şekli, grafit/matris oranı, grafit boy/en oranı, matris yapısı ve tane boyutu gibi mikro ve makro yapısal özellikler önemli rol oynamaktadır. Buradan hareketle, hedeflenen parçanın üretimi için planlanan VGDD malzemenin üretilebilmesi amacıyla planlanan işlemler uygulandığında;

$>$ \% 0.3-0.8 oranlarında Ver-Mat malzemesi ilave edildiğinde, küresel grafitlerin \% 45-50 oranında vermikülerleştirilebildiği,

$>$ \% 0.3-0.8 oranlarında aşılayıcı ilave edildiğinde tane boyutunun \% 45 oranında azaltılabildiği,

$>\% 0.5 \mathrm{Cu}$ ilave edildiğinde $\mathrm{G}+$ Ferritik (ortalama \% $12+87$ ) olan matrisin, vermikülerleştirici ilavesiyle G+ağılıklı Ferritik+Perlitik (ortalama \% 9-11 + 79-81 + 8-10) ve Cu ilavesiyle birlikte ise G+Ferritik+Perlitik (ortalama \% 9-11 + 48-49 + 40-41) hale dönüştürülebildiğí,

$>$ grafit boy/en oranının vermikülerleşmenin artmasıyla \% 35 oranında geliştirilebildiği,

$>$ grafit hacim oranının ortalama \% 10-12 oranında tutulabildiği görülmüştür.

Sonuç olarak; hedef parça olan tren fren diskine uygun özelliklerde malzeme üretmeyi hedefleyen bu çalışma neticesinde, yeterli oranda vermiküler grafit yapısında ve uygun ferritik / ferrit+perlitik matriste VGDD üretiminin yapılabildiği tespit edilmiştir. 


\section{TEŞEKKÜR (ACKNOWLEDGEMENT)}

Bu çalışmada kullanılan numunelerin dökümünde sağladıkları katkı ve yardımlarından dolayı Yeşilyurt Döküm Makine Sanayi'ne teşekkür ederiz.

\section{KAYNAKLAR (REFERENCES)}

[1] Walton, C.F. and Opar, T.J. (Eds), "Iron Castings Handbook", Iron Castings Society, Cleveland, Ohio, 1981.

[2] Visnapuu, A., Betts, B. A. and Neumeier, L. A., "Influence of graphite morphology on the damping properties of selected cast iron structures", Rolla Research Centre, Bureau of Mines, U.S. Dept of Interior, Rolla, Mo. 65401, USA, 1977.

[3] Schelleng, R. D., "Cast iron with at least $50 \%$ of the graphite in vermicular form and process for making same", United States Patent 3, 421, 886, 14 January 1969.

[4] Subramanian, S. V. and Genualdi, A. J., "Optimization of damping capacity and strength in hypereutectic grey cast iron”, AFS Paper 96-138, American Foundrymen’s Society, pp. 1-2, 1996.

[5] Zych, J. and Żyrek, A., "Vermicular cast iron production in the "Inmold" technology (in the Metalpol casting house) and the assessment of its thermal fatigue resistance", Archives of Foundry Engineering, 11 (3), 255-260, 2013.

[6] Riposan, I., Chisamera, M., Stan, S. and Skaland, T., "Surface Graphite Degeneration in Ductile Iron Castings for Resin Molds", Tsinghua Science And Technology, 13 (2),157-163, 2008.

[7] Gen, Z., and Wanhua, L., "Production technique of vermicular graphite iron cylinder head of vehicle diesel engine-Special Review", China Foundry, 5 (3), 153-161, 2008.

[8] Craig, D.B., Hornung, M.J. and McCluhan, T.K., "Grey Iron”, ASM Handbook, Vol. 15, 644-655, 1988.

[9] Blackmore, P.A. and Morton, K., "Structure-property relationships in graphite cast irons", Int. J. Fatigue, 149-155, July 1982.

[10] Gorny, M. and Kawalec, M., "Effects of Titanium Addition on Microstructure and Mechanical Properties of Thin-Walled Compacted Graphite Iron Castings", JMEPEG, 22, 1519-1524, 2013.

[11] Soiński, M.S., Jakubus, A. and Stradomski, G., "The Influence of Aluminium on the Spheroidization of Cast Iron Assessed on the Basis of Wedge Test", Archives of Foundry Engineering, 13 (2), 163-168, 2013.

[12] Imasogie B.I., "Microstructural Features and Mechanical Properties of Compacted Graphite Iron Treated With Calcium-Magnesium Based Masteralloy", ASM International JMEPEG 12, 239-243, 2003.

[13] Erfan, O. M. and Elmabrouk, O., "Influence of Section Thickness on the Thermal Conductivity of Compacted Graphite Cast Iron at Elevated Temperatures", International Journal of Engineering and Innovative Technology (IJEIT), 3 (7), 29-33, 2014.

[14] Dawson, S., "Compacted Graphite Iron: Mechanical and Physical Properties for Engine Design", Based on a paper presented at: Werkstoff und Automobilantrieb (Materials in Powertrain VDI 
(Verein Deutscher Ingenieure) Dresden Germany 28-29 October 1999, http://www.sintercast.com/file/cgi-mechanical-and-physical-properties-for-engine-design-1.pdf

[15] Indra, F. And Tholl, M., "Compacted graphite iron (CGI) - A new material for internal combustion engines", Fifth Aachen Colloquium on Vehicles and Automobile Technology, 331-350, 1995.

[16] Hughes, I.C.H. and Powell, J., "Compacted Graphite Irons - High quality engineering materials in the cast iron family", SAE Paper 840772, 1984.

[17] Altstetter, J.D. and Nowicki, R.M., "Compacted Graphite Iron - Its properties and automotive applications", AFS Transactions 82-188, pp. 959-970, 1982.

[18] Loper, C.R., Lalich, M.J., Park, H.K. and Gyarmaty, A.M., "The relationship of microstructure to mechanical properties in compacted graphite irons", AFS Transactions 80-160, pp. 313-330, 1980.

[19] Stefanescu, D.M. Hummer, R. and Nechtelberger, E., "Compacted Graphite Irons", Metals Handbook, Ninth Edition, Vol. 15, pp. 667-677, 1988.

[20] Okamoto, T., Kagawa, A., Kamei, K. and Matsumoto, H., "Effect of graphite shape on thermal conductivity, electrical resistivity, damping capacity and Young's modulus of cast iron below $500^{\circ} \mathrm{C}^{\prime}$, Journal of Japan Foundrymen's Society, (55) 2, 107-112, 1983.

[21] Tanaka, Y., Saito, H. And Ikawa, K., "Relation between graphite structure and physical and mechanical properties of compacted/vermicular graphite cast iron”, Journal of Japan Foundrymen's Society, ( 53) 4, 187-192, 1981.

[22] Sinter Cast Nodularity Rating Charts, SinterCast, 1997.

[23] Gu, Y., "Engine cylinder block", Ford Motor Company Ltd, European Patent Application EP 0769 615 A1, (April 23), 1997.

[24] Ruff, G.F., "Mechanical properties of compacted graphite cast iron”, SAE Paper 810209, 1981.

[25] Guesser, W., Masiero, I., Melleras, E. and Cabezas, C. S., "Thermal Conductivity of Gray Iron and Compacted Graphite Iron Used for Cylinder Heads”, Revista Matéria, (10) 2, 265-272, 2005.

[26] Geier G.F., Bauer, W., McKayb, B.J. and Schumacher P., "Microstructure Transition From Lamellar To Compacted Graphite Using Different Modification Agents" Materials Science and Engineering A 413-414, 339-345, 2005.

[27] Elbel, T. and Hampl, J., "Influence Of Al And Ti On Microstructure And Quality Of Compacted Graphite Iron Castıngs", METABK, 48(4), 243-247, 2009.

[28] Hasırcı, H., "Mekanik Titreşimin Küresel Grafitli Dökme Demirlerin Mikroyapı Ve Mekanik Özelliklerine Etkileri” Politeknik Dergisi, 20 (2), 275-282, 2017. 